\title{
Spatial variability of aquatic plant and microfaunal seed and egg bank communities within a forested floodplain system of a temperate Australian river
}

\author{
Jorge L. Portinho ${ }^{1}$ Daryl L. Nielsen ${ }^{2,3,4} \cdot$ Nathan Ning $^{2,4} \cdot$ Warren Paul $^{4}$ • \\ Marcos Nogueira ${ }^{1}$
}

Received: 23 May 2016/Accepted: 23 November 2016/Published online: 29 November 2016

(C) Springer International Publishing 2016

\begin{abstract}
Aquatic plant and microfaunal propagule banks represent a major source of regenerative potential in riverfloodplain ecosystems. This study investigated the spatial patterns of microfaunal and aquatic plant propagule bank communities within a wetland complex on the forested floodplain of a temperate Australian river system that had recently been completely inundated and dried again. Microfaunal emergence and aquatic plant germination were examined at the wetland complex spatial scale by incubating sediment samples collected from ten sites, randomly distributed within a $30 \mathrm{~km}^{2}$ area of floodplain. Spatial (northing, easting and elevation) and environmental variables [commence-to-flow (CTF), \%clay, \%silt and $\%$ moisture] were also examined at each site to assist in describing the spatial patterns of the propagule banks across the floodplain. It was predicted that the microfaunal and aquatic plant propagule bank communities would be
\end{abstract}

Electronic supplementary material The online version of this article (doi:10.1007/s00027-016-0514-z) contains supplementary material, which is available to authorized users.

Jorge L. Portinho

jorgeportinho@gmail.com

Daryl L. Nielsen

daryl.nielsen@csiro.au

1 Department of Zoology, São Paulo State University (UNESP), Distrito de Rubião Júnior s/n 18610-970, Botucatu, São Paulo, SP, Brazil

2 The Murray-Darling Freshwater Research Centre, University Drive, Wodonga, VIC 3690, Australia

3 CSIRO Land and Water Flagship, University Drive, Wodonga, VIC 3690, Australia

4 La Trobe University, University Drive, Wodonga, VIC 3690, Australia homogeneously distributed at the wetland complex scale in response to the recent widespread flooding. In contrast to our prediction, microfaunal and plant propagule bank communities varied among most sites, with this variation best explained by location (northing) and elevation (which was related to site CTF). This suggests that microfaunal and plant propagule bank communities are heterogeneously distributed in forested floodplain systems, even following widespread flooding events.

Keywords Egg bank - Seed bank · Floodplain . Resilience $\cdot$ Spatial distribution

\section{Introduction}

It is well accepted that microfauna and wetland plants are capable of persisting within resting stages (or dormant propagule banks) in wetland sediments (Brock et al. 2003). Both types of propagule banks act as mechanisms for persistence in temporally varying environments, and play a key role in promoting resilience against unfavourable environmental conditions (Brock et al. 2003; Gyllström and Hansson 2004). In addition to promoting resilience, propagule banks play a key role in influencing the population and community dynamics, seasonal succession, biogeographic patterns, and the evolution of populations (De Stasio 1990; Warr et al. 1993; Brock 2011).

Despite the widely accepted importance of propagule banks in the ecology of aquatic plant and microfaunal communities, most of the existing knowledge regarding the spatial patterns of aquatic plants and microfauna is heavily biased towards their active communities (i.e. the non-dormant aboveground floodplain vegetation and microfauna in water column) (Shiel et al. 1998; Smith and Haukos 2002; Jeffries 
2008). Nevertheless, the studies that have been published thus far relating to propagule banks suggest that their spatial patterns are primarily governed by the production of the propagules, and via inputs from dispersal (Hairston et al. 1995; Brock 2011). Propagule production and dispersal vary depending on establishment success (Hairston et al. 1995) and propagule dispersal capacity (Van Den Broek et al. 2005). Successful establishment occurs when potentially viable individuals are able to emerge, recruit and reproduce under suitable environmental conditions (Bonis et al. 1995; Brock et al. 2003; Capon and Brock 2006; Lopes et al. 2016).

Hydrological conditions are thought to be pre-eminent in influencing the establishment success and dispersal capacity of aquatic plant and microfaunal propagules (Casanova and Brock 2000; Capon and Brock 2006; Battauz et al. 2015; Webb et al. 2006). During low water periods, floodplain systems often become a mosaic of wetland patches isolated within the landscape and disconnected from the main river channel. Local factors (e.g. predation, competition, water quality) become more influential in shaping community composition (Cottenie et al. 2003; Bornette and Puijalon 2011) and contribute to spatial heterogeneity in the active community (Casanova and Brock 2000; Paggi and Paggi 2008), which subsequently adds to spatial heterogeneity in the dormant community (Shiel et al. 1998; Campbell et al. 2014). By contrast, during high water periods when entire floodplain areas become inundated, water flow action is expected to promote propagule dispersal (Jenkins and Boulton 2003; Merritt and Wohl 2002; Nilsson et al. 2010; Battauz et al. 2015) and consequently homogenise propagule bank communities at a wetland complex (i.e. a group of wetlands that become highly connected during periods of inundation) spatial scale (Haukos and Smith 1993; Thomaz et al. 2007; Bozelli et al. 2015). The high flows can also aid in restoring sediment conditions (e.g. soil moisture content) to support the viability of dormant seeds and eggs (O'Donnell et al. 2015; Jenkins and Boulton 2007), although the influence of such flows is likely to vary among floodplain locations with differing elevations and/or commenceto-flow (CTF) thresholds (Tronstad et al. 2005; Capon and Brock 2006).

This study tested the prediction that microfaunal and aquatic plant propagule bank communities would be homogeneously distributed at the wetland complex scale in response to recent widespread flooding within an Australian forested floodplain system, and that their spatial patterns would be related to commence-to-flow thresholds on the floodplain. The forested floodplain system consists of a diversity of wetland patches, which include billabongs, rush lands, grasslands and lakes. Spatial (northing, easting and elevation) and environmental [commence-to-flow (CTF), \% clay, $\%$ silt and $\%$ moisture] variables were also examined to assist in describing the spatial patterns of the propagule banks. The study area had been influenced by persistent drought conditions from 2000 through to 2010 (Whitworth et al. 2012), causing the majority of study area to remain dry for this period (Ward pers. comm.). Widespread flooding from mid-2010 to late-2012 inundated the entire floodplain of the study area, before the floodwaters receded again by March 2013 when the study was undertaken.

\section{Methods}

\section{Study area}

The study was undertaken on the Barmah-Millewa Forest (BMF) floodplain of the Murray River in south-eastern Australia (Fig. 1). The BMF covers an area of 66,000 ha, and consists of a mosaic of semi-permanent and ephemeral lakes, swamps and channels. The surrounding vegetation is comprised of river red gums (Eucalyptus camaldulensis), with a diverse understory plant community. Between 2000 and 2010, the BMF was subjected to persistent drought conditions and associated low flows (see online resource 1 Fig. S1). This situation came to an abrupt end in late 2010, with near-record spring and summer rainfall causing the drought to be broken by a series of widespread flood events throughout the BMF (see more details in MDBA 2012; Whitworth et al. 2012).

\section{Site selection}

A $5 \mathrm{~km}$ by $6 \mathrm{~km}$ sampling area was selected within the BMF based on the abundance of small wetlands and braided channels (flood-runners) that distribute floods waters throughout the forest (Fig. 1). This area was then divided into $1 \mathrm{~km}^{2}$ grids, from which 10 were randomly selected for sampling. Each $1 \mathrm{~km}^{2}$ grid, or site, was then divided into one hundred $0.1 \mathrm{~km}^{2}$ quadrats from which five were randomly chosen for sediment collection (Fig. 1). Thus, a total of 50 samples (i.e. 10 sites $\times 5$ quadrats) were collected across the study area.

\section{Sediment collection for assessing propagule bank communities}

Sediment samples were collected from each quadrat between 19 March and 16 May 2013. Within each quadrat, samples were randomly collected by shovelling the top $3 \mathrm{~cm}$ of sediment until approximately $10 \mathrm{~kg}$ of sediment had been collected and placed in a plastic bag following the methods of Nielsen et al. (2003, 2007) and Brock et al. (2005). Published reports of seed and egg bank sampling have shown that only the top three centimetres of sediment is required for representing different communities present 
Fig. 1 Schematic representation of the experimental design showing the location of the BMF and the spatial arrangement of the 10 sites within the $30 \mathrm{~km}^{2}$ study area. Grey colour limitation area of the BMF

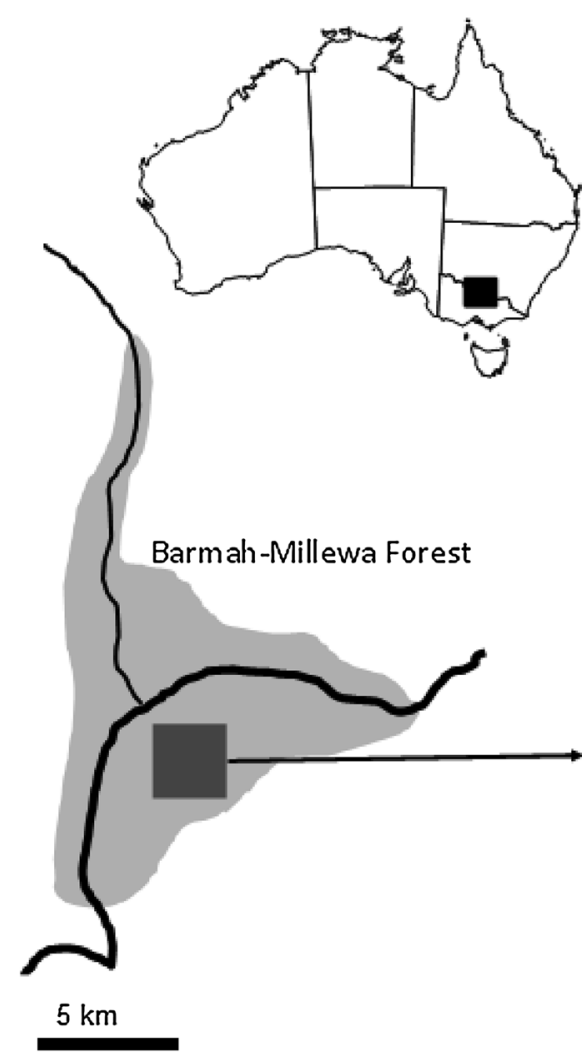

$1 \mathrm{~km}$
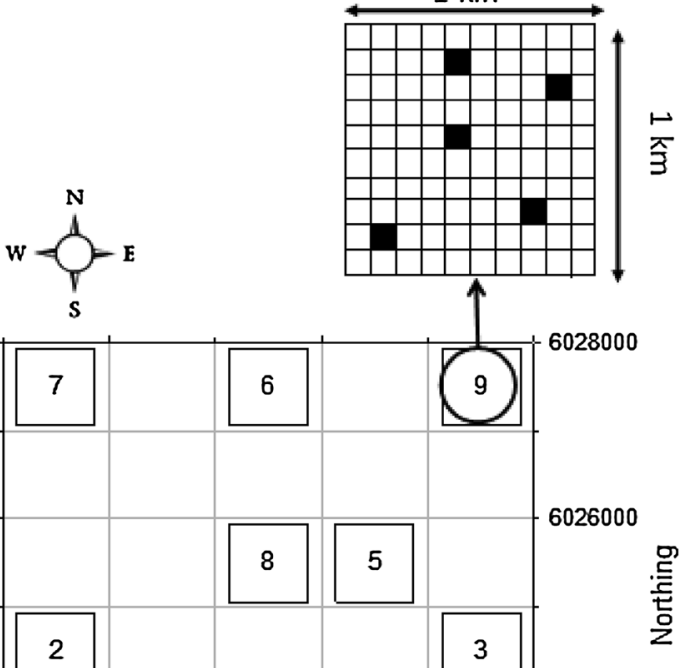

in wetlands (Cáceres 1998). The sediment was taken back to the Murray-Darling Freshwater Research Centre in Wodonga (Victoria), where it was gently crushed and air dried, before being sieved through a $500 \mu \mathrm{m}$ mesh-size. Careful crushing of the sediment ensures that the propagules can be uniformly mixed, and does not affect propagule germination or emergence (Nielsen et al. 2008; Ning et al. 2008). Furthermore, drying and sieving guarantees that only dormant propagules remain prior to sub-sampling for use in the emergence/germination trials (Nielsen et al. 2008; Ning et al. 2008).

Two-hundred-and-fifty grams (dry weight) of wetland sediment were placed into individual trays $(17 \times 12 \times$ $5.8 \mathrm{~cm}$ ). For both microfauna and aquatic plants, three replicate subsamples were taken from each of the 50 samples, resulting in an experimental design using 300 subsamples (150 for microfauna and 150 for aquatic plants).

\section{Microfauna}

Sediment samples were incubated in a constant temperature room with a temperature set at $25{ }^{\circ} \mathrm{C}$, and a 12:12 h light/dark cycle to optimise hatching and germination conditions, following the protocol described in Ning and Nielsen (2011). Samples were inundated with aged tap water and gently oxygenated using aquarium bubblers. Each tray was sampled twice weekly for a period of 28 days by gently pouring the water from each tray through a $50 \mu \mathrm{m}$ sieve, with minimum disturbance to the sediment (Nielsen et al. 2007). Twenty-eight days has been shown to be sufficient for overall hatching success as a prerequisite in microfauna richness and diversity studies (Boulton and Lloyd 1992; Vandekerkhove et al. 2005; Ning and Nielsen 2011), and twice weekly sampling minimizes the potential for reproduction by any individuals that emerge (Nielsen et al. 2007, 2008). On each occasion, the collected sample was put into a $200 \mathrm{ml}$ storage jar and preserved in $70 \%$ ethanol, while the sediment remaining in each incubation container was re-inundated with aged tap water. At the end of the 28 day period all samples from each container were combined into a single sample. Microfaunal samples were sub-sampled prior to processing. One-millilitre aliquots were successively placed into a SedgewickRafter counting chamber, and identified and counted using dark field microscopy until either a minimum of 300 individuals or $20 \%$ of the sample had been analysed. These sample processing criteria are sufficient to detect any rare taxa that emerge (Shiel et al. 1998; Nielsen et al. 2007, 2008; Ning et al. 2008; Ning et al. 2015). All microfauna were identified to the level of Family or Genus. Identification to either of these taxonomic levels has been shown to be suitable for detecting changes in microfaunal communities in response to environmental 
change (Nielsen et al. 1998). Taxa were identified using relevant keys in Shiel (1995).

\section{Aquatic plants}

As previous germination studies have indicated that fewer species germinate under flooded conditions compared to damp conditions (Capon and Brock 2006), the sediments were exposed to a single damp treatment. Plant germination trays were inundated with aged tap water to a depth of $2 \mathrm{~cm}$, and maintained at this depth for a period of 12 weeks. At the end of the 12-week period, all emergent plant seedlings were identified and taxon richness and abundance recorded for each tray. Identification and nomenclature of angiosperms and ferns followed Harden (1990-1993) and Cunningham et al. (1992). Liverwort identification followed Sainty and Jacobs (2003).

\section{Spatial attributes}

Easting, northing and elevation (mASL) for each site were determined using the Barmah Forest Digital Elevation Model (Water_Technology 2011). Geographic proximity was inferred from northing and easting position at each site (UTM zone 55) (Table 1; Fig. 1).

\section{Environmental attributes}

CTF thresholds were defined as the magnitude of flow within the Murray River channel upstream of the BMF at Tocumwal required to inundate each site using the Barmah Forest Digital Elevation Model (Water_Technology 2011). Individual CTF thresholds will depend on the wetland's elevation on the floodplain, its distance from the river and the nature of its connection channels (MDBA 2012). Flooding of the BMF is highly regulated via the use of regulators and levees that prevent water flowing onto the floodplain, allowing the water level in the main river channel to be maintained at capacity without loss of water. Once inflows exceed $11,000 \mathrm{ML} \mathrm{day}^{-1}$ upstream of the forest at Tocumwal, regulators are opened and flooding occurs. Flows greater than $60,000 \mathrm{ML} \mathrm{day}^{-1}$ exceed the capacity of the River Murray through the BMF and result in flooding of the forest's wide range of floodplain swamps, marshes, billabongs, rush lands, grasslands and lakes (Fig. S1).

Sediment characteristics were assessed at each site by measuring the percentage of silt, clay and moisture using standard methods described in Grimshaw (1989) (Table 1).

\section{Data analysis}

Aquatic plant and microfaunal abundance and richness were assessed in each tray and the three subsample trays from each quadrat were averaged to give a mean number of plants and microfauna per tray for each quadrat. The five quadrats were then used as replicates for each site. Aquatic plant and microfaunal densities were expressed as propagules per $\mathrm{m}^{2}$ in all descriptive tables and figures.

The mean and the variance components for each of the environmental variables (\%clay, \%silt, \%moisture, and CTF), as well as bivariate associations with easting, northing, and elevation were estimated using linear mixed effects models (Pinheiro and Bates 2000). Site was included as a random effect to account for the two-stage cluster (hierarchical) sampling design - where ten $1 \mathrm{~km}^{2}$ were randomly selected from the $30 \mathrm{~km}^{2}$ sampling area and then five $0.01 \mathrm{~km}^{2}$ quadrats were randomly selected from each of those ten sites. Spatial trends in the environmental variables and elevation were also tested using linear mixed effects models, with easting, northing, and their interaction included in the models as fixed effects. Residual diagnostic plots were examined to ensure the data were consistent with the assumptions of the linear mixed effects model. These analyses were performed using the linear mixed effects (nlme) function in R (Pinheiro et al. 2016; R Development Core Team, 2016).

Table 1 Spatial and environmental (average and SE) descriptors for the 10 sites within the BMF

\begin{tabular}{llllllrr}
\hline Sites & Easting & Northing & Elevation $(\mathrm{m})$ & CTF $\left(\mathrm{ML} \mathrm{day}^{-1}\right)$ & \% Clay & \% Silt & \% Moisture \\
\hline S1 & 323,500 & $6,022,500$ & 95.07 & 39,000 & $30.00(1.11)$ & $17.80(2.05)$ & $15.58(2.74)$ \\
S2 & 321,500 & $6,024,500$ & 95.79 & 62,000 & $37.64(2.22)$ & $16.92(3.21)$ & $15.16(2.13)$ \\
S3 & 325,500 & $6,024,500$ & 96.44 & 52,333 & $20.56(1.47)$ & $11.44(3.53)$ & $21.36(1.80)$ \\
S4 & 324,500 & $6,022,500$ & 96.03 & 48,000 & $22.00(1.59)$ & $17.04(1.77)$ & $14.94(3.56)$ \\
S5 & 324,500 & $6,025,500$ & 95.61 & 42,800 & $29.60(2.30)$ & $13.92(2.91)$ & $21.48(2.53)$ \\
S6 & 323,500 & $6,027,500$ & 95.01 & 25,800 & $30.40(2.70)$ & $17.56(3.35)$ & $15.38(3.38)$ \\
S7 & 321,500 & $6,027,500$ & 94.71 & 20,000 & $28.52(3.22)$ & $20.12(4.85)$ & $15.1(8.80)$ \\
S8 & 323,500 & $6,025,500$ & 95.66 & 33,000 & $31.92(2.84)$ & $15.96(4.25)$ & $18.7(3.43)$ \\
S9 & 325,500 & 6027500 & 96.12 & 44,000 & $34.40(1.33)$ & $19.92(0.99)$ & $15.96(2.05)$ \\
S10 & 325,500 & $6,023,500$ & 95.50 & 24,250 & $22.80(2.30)$ & $13.56(3.03)$ & $24.68(2.70)$ \\
\hline
\end{tabular}

Projected coordinate system: GDA_1994 Universal Transverse Mercator zone 55 
Analyses of community data were undertaken using the software program PRIMER (version 7) with the PERMANOVA + add-on (Anderson et al. 2008). Permutational Multivariate Analysis of Variance (PERMANOVA) is a method for testing the multivariate null hypothesis of no difference in centroids among groups (with adjustment for covariates if necessary) from a between-samples resemblance matrix calculated from multivariate species data. We used the Bray-Curtis similarity coefficient, since it is not affected by joint absences, takes the value of 0 when two samples share no species and the value 100 when two samples are identical, and it has the flexibility to register differences in total abundance when the relative abundances of two samples may be identical (Clarke et al. 2014).

Prior to analysis, all data were square-root transformed to emphasise the contribution of rarer taxa (Clarke 1993), and all analyses were based on the Bray-Curtis resemblance measure. Exploratory analyses of aquatic plant and microfaunal community composition patterns were done using Principal Coordinates Analysis (PCO) and a hierarchical cluster analysis using group average linkage (CLUSTER). Pairs of PCO axes were plotted in ordination diagrams to visually examine patterns in community similarities between samples, with vector overlays (Pearson correlations) of spatial and environmental variables indicating correlations between these variables and ordination axes (Anderson et al. 2008). Scatter plots of PCO axes against environmental variables were examined to ensure the relationships were linear prior to using Pearson correlations for the vector overlays.

PERMANOVA was used to test for variation at different spatial scales in seed and egg bank communities, and establish whether there was a trend component to the spatial variation, as well as the degree to which the spatial variation could be explained by the environmental variables. This analysis was undertaken in four steps, with the process of partitioning variation among the spatial and environmental components based on Anderson and Cribble (1998). The PERMDISP routine in the PERMANOVA + add-on (Anderson et al. 2008) was used to check the assumption of homogeneity of dispersions that underlies
PERMANOVA. This assumption was satisfied for the microfauna data set, but for the seed bank data there was one sample in particular that inflated the dispersion for site 5. All analyses for the seed bank community were therefore repeated with and without site 5 to assess the effect of this site on the results, and no appreciable differences in the results were found.

Step 1: A single-factor analysis with 'Site' as a random factor, which was undertaken to test the null hypothesis of no differences in communities among sites.

Step 2: Spatial covariates (easting, northing, elevation) were included to determine the percent variation in communities among and within sites that could be explained by spatial trends. These are given by the percent reduction in the sum of squares for Site and the sum of squares for residual from Step 1 to Step 2.

Step 3: CTF was incorporated as a covariate to determine the percentage of spatial variation (including site, easting, northing, and elevation) in the communities, and residual variation among samples, that could be explained by CTF. These are given by the percent reduction in the spatial sum of squares (i.e. the combined sum of squares for site, easting, northing, and elevation) and the sum of squares for residual from Step 2 to Step 3.

Step 4: Sediment characteristics (\%clay, \%silt and $\%$ moisture) were included as covariates to determine the percentage of spatial variation (including site, easting, northing, and elevation) in the communities, and residual variation among samples, that could be explained by the environmental variables (sediment characteristics and CTF).

\section{Results}

\section{Physical characteristics}

The physical nature of the floodplain and the interaction between landform and numerous braided channels (floodrunners) distributing floodwaters throughout the forest has created a heterogeneous landscape. This heterogeneity is evidenced by the linear mixed effects models for clay, silt,

Table 2 Univariate and bivariate statistics for clay, silt, moisture, and CTF from linear mixed effects models, including the mean, site standard deviation (SD), and residual SD for univariate models, and the slope (and site SD) for bivariate associations with easting, northing, and elevation

\begin{tabular}{|c|c|c|c|c|c|c|}
\hline \multirow[t]{2}{*}{ Variable } & \multicolumn{3}{|c|}{ Univariate statistics } & \multicolumn{3}{|c|}{ Bivariate statistics } \\
\hline & Mean & Site SD & Residual SD & Easting & Northing & Elevation \\
\hline$\%$ Clay & $28.8^{*}$ & $5.3^{*}$ & $3.5^{*}$ & $-1.7\left(5.0^{*}\right)$ & $1.2\left(5.0^{*}\right)$ & $-0.2\left(5.3^{*}\right)$ \\
\hline$\%$ Silt & $16.4^{*}$ & $2.4^{*}$ & $3.1^{*}$ & $-1.0\left(2.0^{*}\right)$ & $0.4(2.3 *)$ & $-2.2\left(2.1^{*}\right)$ \\
\hline$\%$ Moisture & $17.8^{*}$ & $2.9^{*}$ & $4.5^{*}$ & $1.6 *(1.8 *)$ & $-0.5(3.1 *)$ & $1.0(2.9 *)$ \\
\hline CTF $\left(\right.$ ML day $\left.{ }^{-1}\right)$ & $39.1 *$ & $12.7 *$ & $9.7 *$ & $0.2\left(13.5^{*}\right)$ & $-0.3(13.2 *)$ & $13.4^{*}(8.7 *)$ \\
\hline
\end{tabular}

* Significantly different from zero based on $95 \%$ confidence intervals 
moisture, and CTF, which all indicated statistically significant variation among sites (based on 95\% confidence interval estimates for the site random effect, i.e., site standard deviation) (Table 2).

Of the bivariate associations with easting, northing, and elevation, only the association between CTF and elevation was statistically significant (Table 2). The random effect of site was also statistically significant in this model, which indicates that the variation in CTF among sites is not entirely a consequence of differences in elevation. That is, some sites may be located in depressions that are inundated only at relatively high flows.

Further analysis of spatial trends in the environmental variables indicated a statistically significant interaction effect between easting and northing for clay $(\mathrm{P}=0.002)$ and moisture $(\mathrm{P}=0.036)$, as well as statistically significant site standard deviations. There were no clear geographic patterns for silt, CTF, or elevation (Fig. 2a, b).

\section{Microfaunal propagule bank communities}

Forty-one microfaunal taxa emerged from all sites, comprising of 33 Rotifera and 8 microcrustacea. Of these taxa, $50 \%$ only emerged from the sediment of two sites, and only four rotifer taxa (Bdelloids, Cephalodella, Lecane and Dipleuchlanis) and one microcrustacean (Ostracoda) emerged from all sites (Table 3 and see Online resource 2, Table S1).

The first axis (PCO1) explained 29.6\% of the microfaunal variation, while PCO2 $17.5 \%$ and PCO3 9.6\% (Fig. 3a-c). The PCO axis 1 was negatively correlated with clay $(\mathrm{r}=-0.31)$, and northing $(-0.61)$, while $\mathrm{PCO}$ axis 2 was positively correlated with CTF $(\mathrm{r}=0.53)$. PCO axis 3 was negatively correlated with northing $(-0.323)$ (Table 4$)$.

PERMANOVA indicated that there were significant differences in microfaunal communities among sites
$(\mathrm{P}=0.001)($ Table 5), which was shown via hierarchical cluster analysis (Fig. 4a). From the first and second PERMANOVAs for microfaunal taxa in Table 5, it is evident that spatial trends (i.e. easting, northing, and elevation) explained $43 \%$ of the variation among sites, as well as $9 \%$ of the residual variation among samples (within sites). This indicates that the communities are heterogeneously distributed across large spatial (wetland complex) scales, but that they are more homogenous at smaller $\left(1 \mathrm{~km}^{2}\right)$ spatial scales.

From the second and third PERMANOVAs in Table 5, adding CTF to the model explained only $10 \%$ of the variation accounted for by spatial trends and site, and $4 \%$ of the residual variation among samples. Therefore, CTF is not the only explanation for the spatial patterns.

From the second and fourth PERMANOVAs in Table 5, the environmental variables, including CTF, explained $22 \%$ of the variation accounted for by spatial trends and site, and $12 \%$ of the residual variation among samples. Therefore, the environmental variables do not completely explain the spatial patterns. From the fourth PERMANOVA, the environmental variables explained $17 \%$ of the total variation in community structure, while the spatial variables (including site) explained $38 \%$ of the total variation after adjusting for the environmental variables and CTF. This indicates that there are other drivers of the spatial patterns in community structure, beyond the measured sediment characteristics and CTF.

\section{Aquatic plant propagule bank communities}

Twenty-six plant taxa germinated from all sites. Of these taxa, $50 \%$ germinated from 5 or fewer sites and four taxa germinated from all sites (Callitriche sp., Centipeda sp., Elatine sp., Juncus sp.) (Table 3 and see Online resource 2, Table S2).
Fig. 2 Level plots of the predicted a clay and $\mathbf{b}$ moisture content of sediments across the study area (a) \% Clay

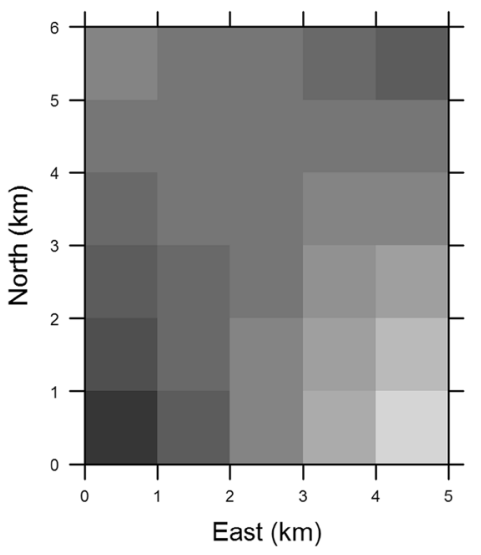

(b) \% Moisture

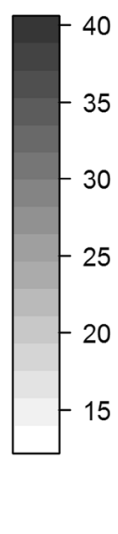

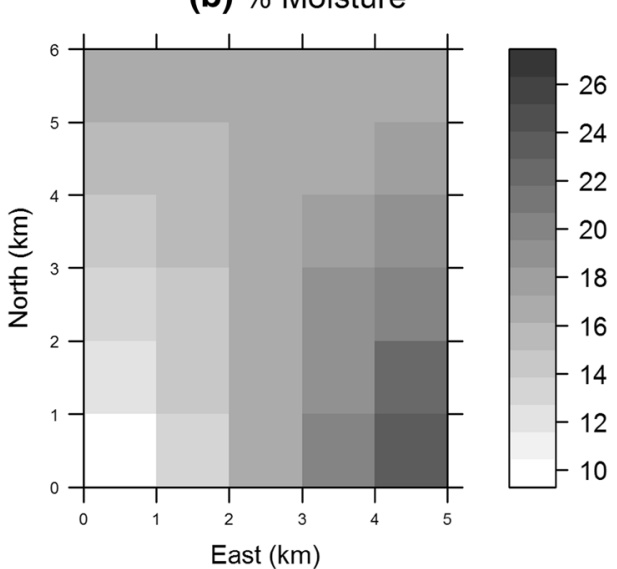


Table 3 Number of sites at which a specific number of microfaunal and aquatic plant taxa occurred, e.g. for microfauna taxa, 8 taxa (20\% of all recorded taxa emerged from only a single site)

\begin{tabular}{|c|c|c|c|c|c|c|c|}
\hline \multicolumn{4}{|c|}{ Microfauna taxa } & \multicolumn{4}{|c|}{ Aquatic plant taxa } \\
\hline Occurrence & $\begin{array}{l}\text { No. of } \\
\text { species }\end{array}$ & $\begin{array}{l}\% \text { of total number } \\
\text { of species }\end{array}$ & $\begin{array}{l}\text { Cumulative } \\
\%\end{array}$ & Occurrence & $\begin{array}{l}\text { No. of } \\
\text { species }\end{array}$ & $\begin{array}{l}\% \text { of total number } \\
\text { of species }\end{array}$ & $\begin{array}{l}\text { Cumulative } \\
\%\end{array}$ \\
\hline 1 & 8 & 20 & 20 & 1 & 5 & 19 & 19 \\
\hline 2 & 12 & 29 & 49 & 2 & 2 & 8 & 27 \\
\hline 3 & 5 & 12 & 61 & 3 & 1 & 4 & 31 \\
\hline 4 & 2 & 5 & 66 & 4 & 3 & 12 & 42 \\
\hline 5 & 3 & 7 & 73 & 5 & 2 & 8 & 50 \\
\hline 6 & 1 & 2 & 76 & 6 & 3 & 12 & 61 \\
\hline 7 & 0 & 0 & 76 & 7 & 4 & 15 & 77 \\
\hline 8 & 4 & 10 & 85 & 8 & 1 & 4 & 81 \\
\hline 9 & 1 & 2 & 88 & 9 & 1 & 4 & 84 \\
\hline 10 & 5 & 12 & 100 & 10 & 4 & 15 & 100 \\
\hline
\end{tabular}
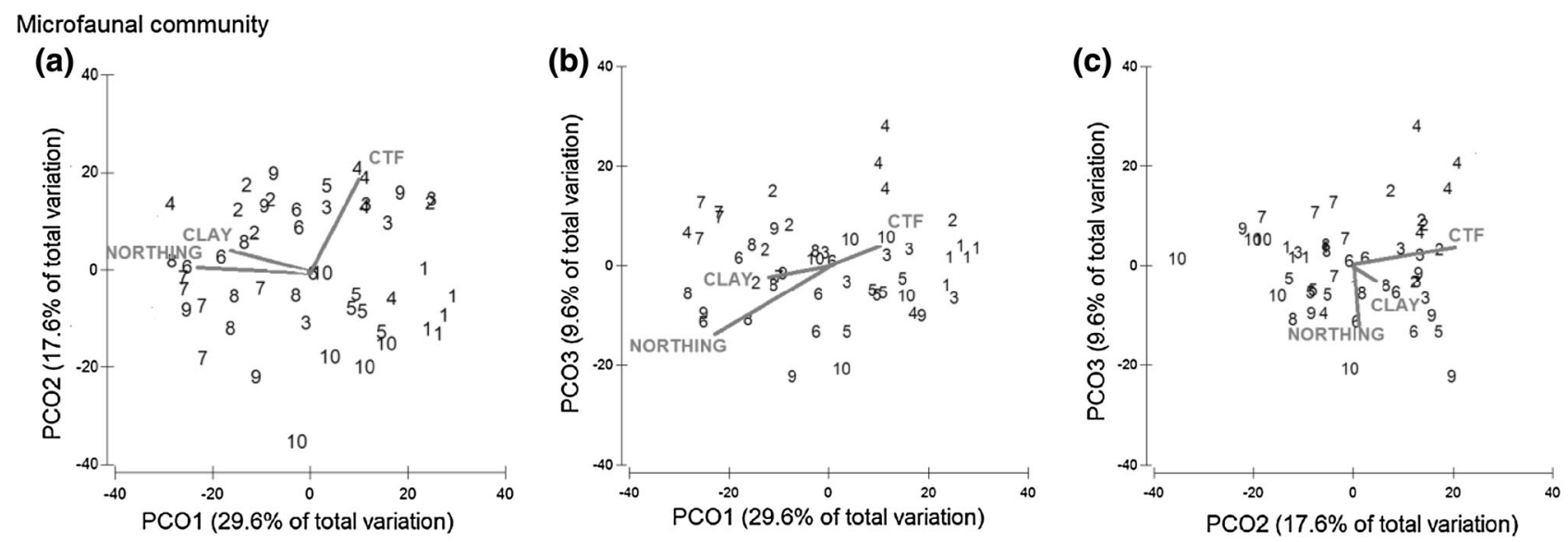

\section{Aquatic plant community}
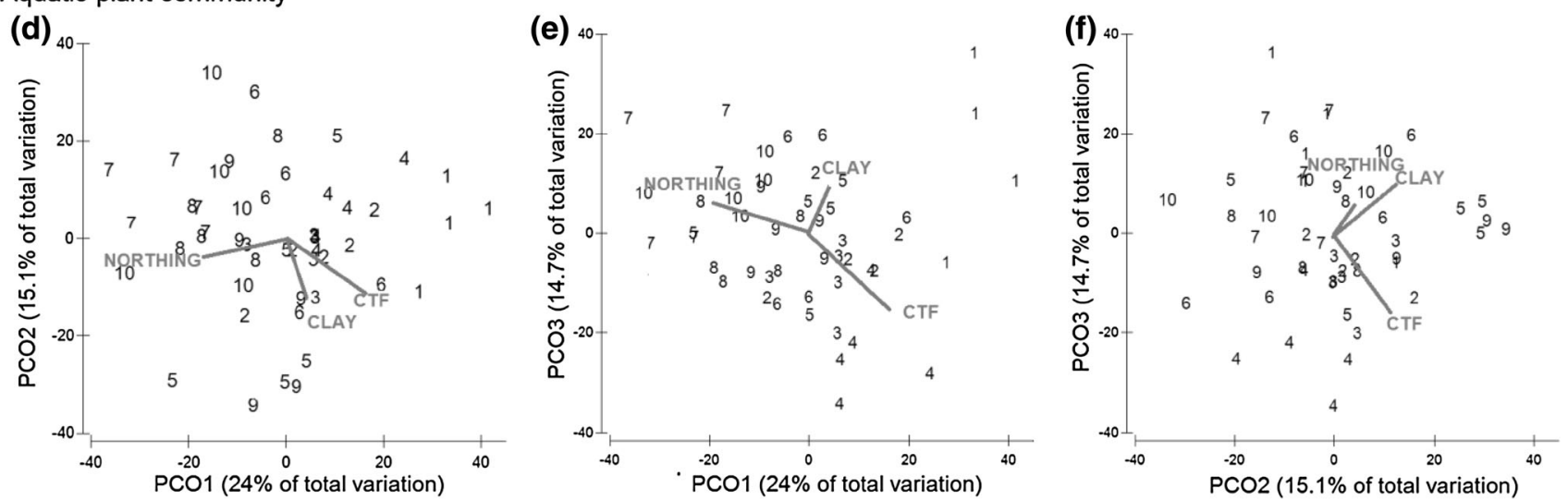

Fig. 3 Principal coordinates analysis (PCO) plots showing ordination sampling sites based on $(\mathbf{a}-\mathbf{c})$ microfauna $(\mathbf{d}-\mathbf{f})$ and aquatic plants abundance and composition data. Spatial and environmental variables

The first three PCO axes mainly represented spatial variation in the aquatic propagule banks communities (Fig. 3d-f). PCO axis 1 (23.9\%) was positively correlated with CTF $(r=0.46)$ and negatively correlated with with a Pearson correlation $>0.3$ with the first three PCO axes are shown. Numbers represent PCO scores for the five quadrats of each site

northing $(-0.52)$, while PCO axis $2(15.1 \%)$ was negatively correlated with clay $(\mathrm{r}=-0.40)$. PCO axis 3 $(14.6 \%)$ was positively correlated with CTF (0.420) (Table 4). 
Table 4 Pearson correlations between spatial and environmental variables and first three PCOs axes

\begin{tabular}{|c|c|c|c|c|c|c|c|c|c|c|c|c|}
\hline \multirow[t]{3}{*}{ Parameter } & \multicolumn{6}{|c|}{ Microfauna taxa } & \multicolumn{6}{|c|}{ Plant taxa } \\
\hline & \multicolumn{2}{|l|}{ PCO 1} & \multicolumn{2}{|l|}{$\mathrm{PCO} 2$} & \multicolumn{2}{|l|}{ PCO 3} & \multicolumn{2}{|l|}{ PCO 1} & \multicolumn{2}{|l|}{ PCO 2} & \multicolumn{2}{|l|}{ PCO 3} \\
\hline & $\mathrm{r}$ & $\mathrm{P}$ & $\mathrm{r}$ & $\mathrm{P}$ & $\mathrm{r}$ & $\mathrm{P}$ & $\mathrm{r}$ & $\mathrm{P}$ & $\mathrm{r}$ & $\mathrm{P}$ & $\mathrm{r}$ & $\mathrm{P}$ \\
\hline Easting & 0.224 & ns & -0.107 & $\mathrm{~ns}$ & 0.151 & ns & -0.131 & ns & 0.193 & ns & 0.151 & ns \\
\hline Northing & -0.608 & $<0.001$ & 0.008 & ns & -0.323 & 0.021 & -0.520 & $<0.001$ & 0.121 & ns & -0.161 & ns \\
\hline Elevation & 0.118 & ns & -0.167 & $\mathrm{~ns}$ & -0.167 & ns & 0.120 & $\mathrm{~ns}$ & 0.279 & $\mathrm{~ns}$ & 0.111 & ns \\
\hline CTF ML day ${ }^{-1}$ & 0.286 & ns & 0.525 & $<0.001$ & 0.155 & ns & 0.456 & $<0.001$ & 0.294 & $\mathrm{~ns}$ & 0.420 & $<0.001$ \\
\hline$\%$ Clay & -0.309 & 0.029 & 0.070 & $\mathrm{~ns}$ & -0.111 & ns & 0.109 & $\mathrm{~ns}$ & -0.405 & 0.004 & -0.243 & ns \\
\hline$\%$ Moisture & 0.275 & ns & -0.190 & ns & -0.009 & ns & -0.136 & ns & -0.018 & ns & -0.003 & ns \\
\hline$\%$ Silt & -0.260 & ns & 0.190 & ns & -0.009 & ns & -0.001 & ns & 0.015 & ns & -0.003 & ns \\
\hline
\end{tabular}

$n s$ not significant

Table 5 PERMANOVA analysis of the microfaunal and aquatic plant communities and their relationships with spatial and environmental variables

\begin{tabular}{|c|c|c|c|c|c|c|c|c|c|}
\hline \multicolumn{5}{|c|}{ Microfaunal community } & \multicolumn{5}{|c|}{ Aquatic plant community } \\
\hline Source & df & SS & MS & $\mathrm{P}$ & Source & df & SS & MS & $\mathrm{P}$ \\
\hline \multicolumn{5}{|l|}{ Variables } & \multicolumn{5}{|l|}{ Variables } \\
\hline Site & 9 & 20588 & 2288 & 0.001 & Site & 9 & 26573 & 2953 & $<0.001$ \\
\hline Residual & 40 & 27005 & 675 & & Residual & 40 & 34672 & 867 & \\
\hline Total & 49 & 47593 & & & Total & 49 & 61245 & & \\
\hline \multicolumn{5}{|l|}{ Spatial } & \multicolumn{5}{|l|}{ Spatial } \\
\hline Easting & 1 & 1857 & 1857 & 0.008 & Easting & 1 & 1929 & 1929 & 0.027 \\
\hline Northing & 1 & 6252 & 6252 & 0.001 & Northing & 1 & 4662 & 4662 & 0.001 \\
\hline Elevation & 1 & 3367 & 3367 & 0.001 & Elevation & 1 & 2733 & 2733 & 0.004 \\
\hline Site & 9 & 11657 & 1295 & 0.001 & Site & 9 & 18948 & 2105 & 0.001 \\
\hline Residual & 37 & 24459 & 661 & & Residual & 37 & 32974 & 891 & \\
\hline Total & 49 & 47593 & & & Total & 49 & 61245 & & \\
\hline \multicolumn{5}{|c|}{ Spatial and environmental (CTF only) } & \multicolumn{5}{|c|}{ Spatial and environmental (CTF only) } \\
\hline CTF ML day ${ }^{-1}$ & 1 & 3271 & 3271 & 0.001 & CTF ML day ${ }^{-1}$ & 1 & 3887 & 3887 & 0.001 \\
\hline Easting & 1 & 1854 & 1854 & 0.003 & Easting & 1 & 1955 & 1955 & 0.029 \\
\hline Northing & 1 & 5782 & 5782 & 0.001 & Northing & 1 & 3254 & 3254 & 0.002 \\
\hline Elevation & 1 & 2084 & 2084 & 0.001 & Elevation & 1 & 2567 & 2567 & 0.006 \\
\hline Site & 9 & 11,034 & 1226 & 0.001 & Site & 9 & 17459 & 1940 & 0.001 \\
\hline Residual & 36 & 23,569 & 655 & & Residual & 36 & 32122 & 892 & \\
\hline Total & 49 & 47,593 & & & Total & 49 & 61245 & & \\
\hline \multicolumn{5}{|c|}{ Spatial and Environmental (All) } & \multicolumn{5}{|c|}{ Spatial and environmental (All) } \\
\hline \% Clay & 1 & 2006 & 2006 & 0.002 & \% Clay & 1 & 3502 & 3502 & 0.001 \\
\hline$\%$ Silt & 1 & 1212 & 1212 & 0.074 & $\%$ Silt & 1 & 275 & 275 & 0.948 \\
\hline$\%$ Moisture & 1 & 1446 & 1446 & 0.022 & $\%$ Moisture & 1 & 723 & 723 & 0.61 \\
\hline CTF ML day ${ }^{-1}$ & 1 & 3408 & 3408 & 0.001 & CTF ML day ${ }^{-1}$ & 1 & 3599 & 3599 & 0.001 \\
\hline Easting & 1 & 1221 & 1221 & 0.07 & Easting & 1 & 1462 & 1462 & 0.13 \\
\hline Northing & 1 & 4438 & 4438 & 0.001 & Northing & 1 & 3383 & 3383 & 0.002 \\
\hline Elevation & 1 & 1774 & 1774 & 0.007 & Elevation & 1 & 2527 & 2527 & 0.003 \\
\hline Site & 9 & 10,514 & 1168 & 0.001 & Site & 9 & 16,129 & 1792 & 0.001 \\
\hline Residual & 33 & 21,573 & 654 & & Residual & 33 & 29,646 & 898 & \\
\hline Total & 49 & 47,593 & & & Total & 49 & 61,245 & & \\
\hline
\end{tabular}


(a)

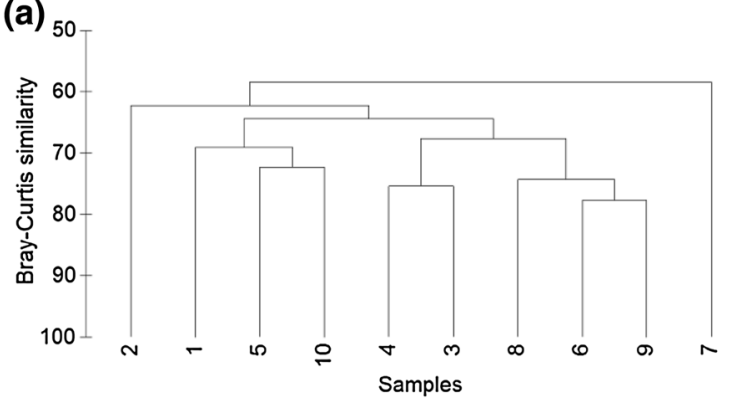

(b)

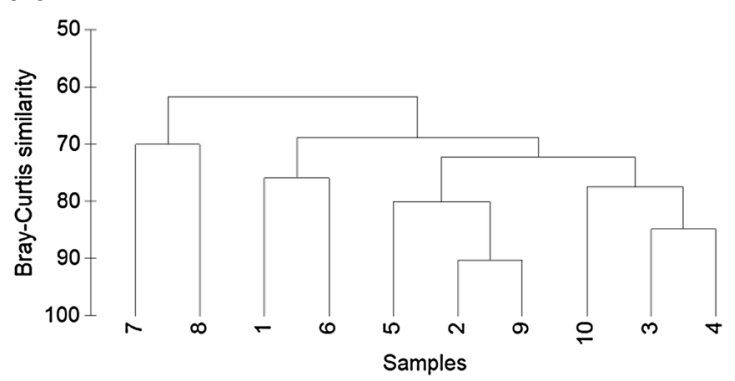

Fig. 4 Hierarchical cluster analysis of $\mathbf{a}$ microfauna and $\mathbf{b}$ aquatic plant abundance and composition data

PERMANOVA indicated that there were significant differences in plant communities among sites $(\mathrm{P}=0.001)$ (Table 5). Overall, the sites grouping were identified by cluster analysis (Fig. 4b). From the first and second PERMANOVAs for plant taxa in Table 5, spatial trends (i.e., easting, northing, and elevation) explained $28 \%$ of the variation among sites and $5 \%$ of the residual variation among samples (within sites).

CTF was incorporated as a covariate and explained $10 \%$ of the variation accounted for by spatial trends and site, and $2 \%$ of the residual variation among samples. Therefore, it explained only part of the proportion of the total variation for the spatial patterns of plant taxa (Table 5). As for microfaunal communities, this suggests that plant communities are heterogeneously distributed across large spatial (wetland complex) scales, but that they are more homogenous at smaller $\left(1 \mathrm{~km}^{2}\right)$ spatial scales.

From the second and fourth PERMANOVAs in Table 5, the environmental variables, including CTF, explained $16 \%$ of the variation accounted for by spatial trends and site, and $10 \%$ of the residual variation among samples. Therefore, the environmental variables do not completely explain the spatial patterns. From the fourth PERMANOVA, the environmental variables explained $13 \%$ of the total variation in community structure, while the spatial variables (including site) explained $38 \%$ of the total variation after adjusting for the environmental variables and CTF. As was true for the microfauna, the measured sediment characteristics and CTF explained only a relatively small proportion of the total variation in the plant propagule community structure, and there are clearly other drivers of the observed spatial patterns.

\section{Discussion}

We predicted that the microfaunal and aquatic plant propagule bank communities would be homogeneously distributed at the wetland complex scale in response to the recent widespread flooding. In contrast to our prediction, the microfaunal and plant communities were heterogeneously distributed among most sites. The degree of community heterogeneity among sites was not strongly associated with geographic proximity, although there was evidence suggesting that communities from sites close to each other and/or with similar CTF thresholds had more similar communities developing.

\section{The spatial patterns of the propagule bank communities in relation to hydrological conditions}

For floodplains that are frequently flooded, water flow action is expected to influence propagule dispersal (Merritt and Wohl 2002; Riis 2008). Seed drift has been shown to be associated with seasonal high flows, thus highlighting the importance of hydraulic factors to the propagule dynamics of seed banks along river margins (Gurnell et al. 2008; Nilsson et al. 2010). Likewise, it has been suggested that the dispersal of microfaunal resting eggs by water is more likely to occur during high water periods, when the habitats are more hydrologically connected, providing a corridor to move among patches at small scales (Jenkins and Boulton 2003). For this study, the BMF was almost continuously flooded between 2010 and 2012, with peak flows of sufficient magnitude to inundate all sites several times (Ning et al. 2013). As a result, it was predicted that the environmental conditions prior to sediment collection would have been ideal for the dispersal of seeds and eggs, and thus the homogenisation of these propagule bank communities (Haukos and Smith 1993; Thomaz et al. 2007; Tockner et al. 2010; Bozelli et al. 2015). Yet, our results indicated that the recent widespread flooding and associated hydrological connectivity did not homogenise the spatial pattern of dormant propagule banks across the BMF floodplain. Indeed, the spatial heterogeneity observed during this study may have been even more pronounced if we had been able to directly identify the resting stages without needing to detect them by incubation sediment. Whilst resting stage incubation is widely accepted among 
microfaunal and plant ecologists as the most practical way of assessing the abundance and composition of viable resting stage communities (e.g. Nielsen et al. 2007; Ning and Nielsen 2011), the approach can potentially mask community heterogeneity by not providing adequate species-specific germination/emergence cues to show existing species composition differences among sites (or treatments) (e.g. Ning and Nielsen 2011).

The spatial heterogeneity detected in microfaunal and aquatic plant propagule bank communities in the floodplain system in this study is more consistent with the findings of other microfaunal resting egg banks and plant propagule banks (Shiel et al. 1998; Bornette et al. 1998; Webb et al. 2006; James et al. 2007; Campbell et al. 2014) that have been undertaken under non-flood conditions, and across much larger spatial scales. It is possible that the forested nature of the floodplain at BMF results in the movement of water across the floodplain being of insufficient velocity to transport propagules over small distances $\left(30 \mathrm{~km}^{2}\right)$. It has been demonstrated that the number of drifting seeds will vary with flow (Merritt and Wohl 2002), and that low flows, in particular, promote the retention of seeds within an area (Riis 2008). Furthermore, within a forested floodplain, retention of drifting propagules will be promoted by physical obstacles such as trees and associated debris that trap the floating propagules (Riis 2008). Thus, plants (Reid et al. 2016) and microfauna (Juračka et al. 2016) may be dispersal-limited in structurally complex landscapes (Middleton 2000), leading to their seeds and eggs not being distributed over large distances, at least in forested floodplain environments. Unfortunately, the sampling design used in this study did not assess the dispersal capacity of the seeds and eggs. Thus, we cannot discard the possibility that flow-influenced propagule traits (e.g. size, floating capacity) were contributing factors for the spatial heterogeneity noted among the propagule bank communities. Future studies that quantitatively assess the role of propagule traits may assist in better understanding the relationship between hydrological conditions and dispersal capacity on the BMF floodplain (Cáceres et al. 2007; Chambert and James 2009; Ślusarczyk et al. 2015).

\section{Propagule bank communities in relation to CTF thresholds and elevation on the floodplain}

There was evidence that propagule communities from sites with similar elevations and corresponding CTF thresholds had more similar communities than those from sites with differing elevations and CTF thresholds. The estimated CTFs thresholds of each site were used to determine when site-specific flooding occurred. Our results showed that sites located in the northern part of the BMF (e.g. S6, S7) are likely to have greater hydrological connectivity and be more frequently inundated due to their lower CTFs and elevation on the floodplain, compared to the other sites. These areas are likely to be more permanently inundated under natural flow regimes. In contrast, the easterly sites (S3, S4 and S10) are higher on the floodplain and thus expected to be less frequently inundated, and when inundation does occur, it is likely to be for shorter durations. Consequently, the high area only rarely floods, and instead remains as an island during most floods.

\section{Propagule bank communities in relation to sediment characteristics}

While the sediment characteristics did not appear to have a major direct influence on the spatial differences among propagule bank communities observed in this study, they may have at least been indicative of potential flooding and sediment deposition effects. Flooding events commonly result in observable gradients in sediment characteristics over short distances parallel and/or perpendicular to a river bed (Scown et al. 2015). The higher percentage of clay and silt at the northern sites compared with the easterly sites may result from recurrent inundation and associated sediment deposition. High sediment loads may result in the smothering and burial of viable seeds and eggs, and have been linked to a reduction in seed germination and microfaunal emergence (Bonis and Lepart 1994; Gleason et al. 2003). In addition, propagule viability decreases with burial depth, with the majority of viable seeds and eggs located within the surface layers of wetland sediment (Grillas et al. 1993; Cáceres 1998). Thus, the spatial variation in propagule banks communities in this study may have been at least partially attributed to the effect of sediment burial on propagule banks.

Flooding also contributes to local changes in the environmental gradients, creating habitats with different characteristics that may influence the species composition, and help to maintain the boundaries of the different taxa within each group (Bonis et al. 1995; Demars and Harper 2005). Observed differences between sites in our study suggest that clay plays an important role in influencing the spatial distribution of aquatic plant seed banks. For instance, amphibious fluctuation-tolerators (e.g. Eleocharis spp.) - a functional group classification suggested by Brock and Casanova (1997) - are aquatic plants, which grow in clay beds on the shores of rivers and lakes, and are most productive during the aquatic phase (Price et al. 2010). In addition, sediments containing a relatively high percentage of clay are able to hold water and nutrients that are essential for maintaining vegetation diversity (Crosslé and Brock 2002), and can influence which species become established by stimulating or suppressing the viability and germination of aquatic plant species (Cherry and Gough 2006). 
We also observed differences in soil moisture content among sites in the BMF. However, the spatial variation in the percentage of soil moisture did not seem to have a detectable influence on the spatial distribution of viable microfaunal and aquatic plant propagule bank communities in our study. A number of studies have argued that soil moisture conditions may have an important influence on the long-term conservation of seed and egg banks, since not all seeds and eggs have the ability to tolerate desiccation for prolonged dry periods without undergoing a loss of viability (O'Donnell et al. 2015; Jenkins and Boulton 2007).

The accumulation of organic matter (e.g. riparian leaf litter) on increasingly dry forested floodplains can lead to major water quality effects after floods (Jenkins and Boulton 2007). As a consequence of the extensive flooding in 2010, the BMF did experience a period of significantly low dissolved oxygen concentrations associated with a 'hypoxic blackwater event' (Whitworth et al. 2012). The period of low dissolved oxygen concentrations and/or toxic leachates may have inhibited emergence from propagule banks in the short term (Jenkins and Boulton 2007; Watkins et al. 2011; Ning et al. 2015), and thus reduced the potential for aquatic plants and microfauna to contribute more resting stages to propagule banks. In addition, the organic matter may have also trapped propagules moving in floodwater or being blown by wind. Consequently, we recommend that any follow-up studies at least quantify the percentage of organic matter in the floodplain sediments as an indicator of the potential influence of hypoxic blackwater events, toxic leachates and/or the inhibition of propagule dispersal.

\section{Conclusion}

Our results suggest that microfaunal and aquatic plant propagule bank communities remain heterogeneously distributed in forested floodplain systems, even following widespread flooding events. This finding is likely to have important implications for understanding and managing the influence of overbank flows on the distribution of aquatic plant and microfaunal communities in floodplain ecosystems. In the BMF, water flows through the area are controlled by regulators and structures, such as canals and earthworks, that were initially designed to prevent the loss of water to the swamp. More recently, environmental water has been used to prolong and extend natural floods. Managing these events requires careful planning to recreate a more natural flood regime (Whitworth et al. 2012; Ning et al. 2015; Nielsen et al. 2015). The provision and maintenance of a variety of hydrological conditions across the landscape will be essential to preserving the natural function and heterogeneity of floodplain seed and egg banks.

Acknowledgements We are grateful to the Brazilian National Council for Scientific and Technological Development (CNPq) and CAPES (Coordination for the improvement of higher education personnel) for financial support to Jorge L. Portinho (doctorate 'sandwich' proc. number- BEX 12951/12-9) and to CNPq for the doctorate scholarship (Proc. Number 152109/2012-9). We would like to thank Jonathan Rout, Rochelle Petrie and Rebecca Durant for their assistance with fieldwork and species identifications. Sediment samples were collected under the National Parks Act 1975 and Flora \& Fauna Guarantee Act 1988 (research permit number 10007412).

\section{References}

Anderson MJ, Cribble N (1998) Partitioning the variation among spatial, temporal and environmental components in a multivariate data set. Aust J Ecol 23:158-167. doi:10.1111/j.1442-9993. 1998.tb00713.x

Anderson MJ, Gorley RN, Clarke KR (2008) Permanova+ for Primer: guide to software and statistical methods. PRIMER-E, Plymouth

Battauz YS, José de Paggi SB, Paggi JC (2015) Endozoochory by an ilyophagous fish in the Paraná River floodplain: a window for zooplankton dispersal. Hydrobiologia 755:161-171. doi:10. 1007/s10750-015-2230-4

Bonis A, Lepart J (1994) Vertical structure of seed banks and the impact of depth of burrial on recruitment in two temporary marshes. Vegetatio 112:127-139

Bonis A, Lepart J, Grillas P (1995) Seed bank dynamics and coexistence of annual macrophytes in a temporary and variable habitat. Oikos 74:81-92. doi:10.1007/bf00044885

Bornette G, Puijalon S (2011) Response of aquatic plants to abiotic factors: a review. Aquat Sci 73:1-14. doi:10.1007/s00027-0100162-7

Bornette G, Amoros C, Lamouroux N (1998) Aquatic plant diversity in riverine wetlands: the role of connectivity. Freshw Biol 39:267-283. doi:10.1046/j.1365-2427.1998.00273.x

Boulton AJ, Lloyd LN (1992) Flooding frequency and invertebrate emergence from dry floodplain sediments of the River Murray, Australia. Regul Rivers 7:137-151. doi:10.1002/rrr.3450070203

Bozelli RL, Thomaz SM, Padial AA, Lopes PM, Bini LM (2015) Floods decrease zooplankton beta diversity and environmental heterogeneity in an Amazonian floodplain system. Hydrobiologia 753:233-241. doi:10.1007/s10750-015-2209-1

Brock MA (2011) Persistence of seed banks in Australian temporary wetlands. Freshw Biol 56:1312-1327. doi:10.1111/j.1365-2427. 2010.02570.x

Brock MA, Casanova MT (1997) Plant life at the edges of wetlands: ecological responses to wetting and drying patterns. In: Klomp N, Lunt I (eds) Frontiers in Ecology: building the links. Elsevier Science, Oxford, pp 181-192

Brock MA, Nielsen DL, Shiel RJ, Green JD, Langley JD (2003) Drought and aquatic community resilience: the role of eggs and seeds in sediments of temporary wetlands. Freshw Biol 48:1207-1218. doi:10.1046/j.1365-2427.2003.01083.x

Brock MA, Nielsen DL, Crosslé K (2005) Changes in biotic communities developing from freshwater wetland sediments under experimental salinity and water regimes. Freshw Biol 50:1376-1390. doi:10.1111/j.1365-2427.2005.01408.x 
Cáceres CE (1998) Interspecific variation in the abundance, production, and emergence of Daphnia diapausing eggs. Ecology 79:1699-1710. doi:10.1890/00129658(1998)079[1699:IVITAP]2.0.CO;2

Cáceres CE, Christoff AN, Boeing WJ (2007) Variation in ephippial buoyancy in Daphnia pulicaria. Freshw Biol 52:313-318. doi:10. 1111/j.1365-2427.2006.01695.x

Campbell CJ, Johns CV, Nielsen DL (2014) The value of plant functional groups in demonstrating and communicating vegetation responses to environmental flows. Freshw Biol 59:858-869. doi:10.1111/fwb.12309

Capon SJ, Brock MA (2006) Flooding, soil seed bank dynamics and vegetation resilience of a hydrologically variable desert floodplain. Freshw Biol 51:206-223. doi:10.1111/j.1365-2427.2005. 01484.x

Casanova MT, Brock MA (2000) How do depth, duration and frequency of flooding influence the establishment of wetland plant communities? Plant Ecol 147:237-250. doi:10.1023/A: 1009875226637

Chambert S, James C (2009) Sorting of seeds by hydrochory. River Res Appl 25:48-61. doi:10.1002/rra.1093

Cherry JA, Gough L (2006) Temporary floating island formation maintains wetland plant species richness: the role of the seed bank. Aquat Bot 85:29-36. doi:10.1016/j.aquabot.2006.01.010

Clarke KR (1993) Non-parametric multivariate analyses of changes in community structure. Aust J Ecol 18:117-143. doi:10.1111/j. 1442-9993.1993.tb00438.x

Clarke KR, Gorley RN, Somerfield PJ, Warwick RN (2014) Change in marine communities: an approach to statistical analysis and interpretation, PRIMER-E, Plymouth

Cottenie K, Michels E, Nuytten N, De Meester L (2003) Zooplankton metacommunity structure: regional vs. local processes in highly interconnected ponds. Ecology 84:991-1000. doi:10.1890/00129658(2003)084[0991:zmsrvl]2.0.co;2

Crosslé K, Brock MA (2002) How do water regime and clipping influence wetland plant establishment from seed banks and subsequent reproduction? Aquat Bot 74:43-56. doi:10.1016/ S0304-3770(02)00034-7

Cunningham GM, Mulham W, Milthorpe PL, Leigh JH (1992) Plants of western New South Wales. Inkata Press, Sydney

De Stasio BT Jr (1990) The role of dormancy and emergence patterns in the dynamics of a freshwater zooplankton community. Limnol Oceanogr 35:1079-1090

Demars BOL, Harper DM (2005) Distribution of aquatic vascular plants in lowland rivers: separating the effects of local environmental conditions, longitudinal connectivity and river basin isolation. Freshw Biol 50:418-437. doi:10.1111/j.1365-2427. 2004.01329.x

Development Core Team R (2016) R: A language and environment for statistical computing. R Foundation for Statistical Computing, Vienna

Gleason RA, Euliss NH Jr, Hubbard DE, Duffy WG (2003) Effects of sediment load on emergence of aquatic invertebrates and plants from wetland soil egg and seed banks. Wetlands 23:26-34

Grillas P, Garcia-Murillo P, Geertz-Hansen O et al (1993) Submerged macrophyte seed bank in a mediterranean temporary marsh: abundance and relationship with established vegetation. Oecologia 94:1-6. doi:10.1007/BF00317293

Grimshaw HM (1989) Analysis of soils. In: Allen SS (ed) Chemical analysis of ecological materials. Blackwell Scientific Publications, Oxford, pp 7-45

Gurnell A, Thompson K, Goodson J, Moggridge H (2008) Propagule deposition along river margins: linking hydrology and ecology. J Ecol 95:553-565. doi:10.1111/j.1365-2745.2008.01358.x

Gyllström M, Hansson L (2004) Dormancy in freshwater zooplankton: induction, termination and the importance of benthic-pelagic coupling. Aquat Sci 66:274-295. doi:10.1007/s00027-004-0712y

Hairston NGJ, Van Brunt RA, Kearns CM (1995) Age and survivorship of diapausing eggs in a sediment egg bank. Ecology 76:1706-1711. doi:10.2307/1940704

Harden GJ (1990-1993) Flora of NSW, vol 1-4. University Press, Kensington, New South Wales

Haukos DA, Smith LA (1993) Seed bank composition and predictive ability of field vegetation in playa lakes. Wetlands 13:32-40. doi:10.1007/BF03160863

James CS, Capon SJ, White MG, Rayburg SC, Thoms MC (2007) Spatial variability of the soil seed bank in a heterogeneous ephemeral wetland system in semi-arid Australia. Plant Ecol 190:205-217. doi:10.2307/40212910

Jeffries M (2008) The spatial and temporal heterogeneity of macrophyte communities in thirty small, temporary ponds over a period of 10 years. Ecography 31:765-775. doi:10.1111/j. 0906-7590.2008.05487.x

Jenkins KM, Boulton AJ (2003) Connectivity in a dryland river: short-term aquatic microinvertebrates recruitment following floodplain inundation. Ecology 84:2708-2723. doi:10.1890/020326

Jenkins KM, Boulton AJ (2007) Detecting impacts and setting restoration targets in arid-zones rivers: aquatic micro-invertebrates responses to reduced floodplain inundation. J Appl Ecol 44:823-832

Juračka PJ, Declerck SA, Vondrák D, Beran L, Černý M, Petrusek A (2016) A naturally heterogeneous landscape can effectively slow down the dispersal of aquatic microcrustaceans. Oecologia 180:785-796. doi:10.1007/s00442-015-3501-5

Lopes PM, Bozelli R, Bini LM, Santangelo JM, Declerck SAJ (2016) Contributions of airborne dispersal and dormant propagule recruitment to the assembly of rotifer and crustacean zooplankton communities in temporary ponds. Freshw Biol 61:658-669. doi:10.1111/fwb.12735

MDBA-Murray-Darling Basin Authority (2012) Assessment of Environmental water requirements for the proposed Basin Plan: Barmah-Millewa Forest. Murray-Darling Basin Authority, Canberra

Merritt DM, Wohl EE (2002) Processess governing hydrochory along rivers: hydraulics, hydrology, and dispersal phenology. Ecol Appl 12:1071-1087. doi:10.1890/1051-0761(2002)012[1071: PGHARH]2.0.CO;2

Middleton B (2000) Hydrochory, seed banks, and regeneration dynamics along the landscape boundaries of a forested wetland. Plant Ecol 146:167-181. doi:10.1023/a:1009871404477

Nielsen DL, Shiel RJ, Smith FJ (1998) Ecology versus taxonomy: Is there a middle ground? Hydrobiologia 387(388):451-457. doi:10.1023/A:1017032900009

Nielsen DL, Brock MA, Crosslé K, Harris K, Healey M, Jarosinski I (2003) The effects of salinity on aquatic plant germination and zooplankton hatching from two wetland sediments. Freshw Biol 48:2214-2223. doi:10.1046/j.1365-2427.2003.01146.x

Nielsen DL, Brock MA, Petrie R, Crosslé K (2007) The impact of salinity pulses on the emergence of plant and zooplankton from wetland seed and egg banks. Freshw Biol 52:784-795. doi:10. 1111/j.1365-2427.2006.01714.x

Nielsen DL, Brock MA, Vogel M, Petrie R (2008) From fresh to saline: a comparison of zooplankton and plant communities developing under a gradient of salinity with communities developing under constant salinity levels. Mar Freshw Res 59:549-559. doi:10.1071/MF07166

Nielsen DL, Cook RA, Ning N, Gawne B, Petrie R (2015) Carbon and nutrient subsidies to a lowland river following floodplain inundation. Mar Freshw Res 67:1302-1312. doi:10.1071/ MF14390 
Nilsson C, Brown RL, Jansson R, Merritt DM (2010) The role of hydrochory in structuring riparian and wetland vegetation. Biol Rev 85:837-858. doi:10.1111/j.1469-185X.2010.00129.x

Ning NSP, Nielsen DL (2011) Community structure and composition of microfaunal egg bank assemblages in riverine and floodplain sediments. Hydrobiologia 661:211-221. doi:10.1007/s10750010-0525-Z

Ning NSP, Nielsen DL, Hillman TJ, Suter PJ (2008) Evaluation of a new technique for characterizing resting stage zooplankton assemblages in riverine slackwater habitats and floodplain wetlands. J Plankton Res 30:415-422. doi:10.1093/plankt/ fbn015

Ning NSP, Gawne B, Cook RA, Nielsen DL (2013) Zooplankton dynamics in response to the transition from drought to flooding in four Murray-Darling Basin rivers affected by differing levels of flow regulation. Hydrobiologia 702:45-62. doi:10.1007/ s10750-012-1306-7

Ning NSP, Petrie R, Gawne B, Nielsen DL, Ress GN (2015) Hypoxic blackwater events suppress the emergence of zooplankton from wetland sediments. Aquat Sci 77:221-230. doi:10.1007/s00027014-0382-3

O'Donnell J, Fryirs K, Leishman MR (2015) Can the sedimentological and morphological structure of rivers be used to predict characteristics of riparian seed banks? Geomorphology 245:183-192. doi:10.1016/j.geomorph.2015.05.030

Paggi SBJ, Paggi JC (2008) Hydrological connectivity as a shaping force in the zooplankton community of two lakes in the Paraná River floodplain. Int Rev Hydrobiol 93:659-678. doi:10.1002/ iroh.200711027

Pinheiro JC, Bates DM (2000) Mixed-effects models in S and S-PLUS. Springer, New York

Pinheiro JD, Bates S, DebRoy D, Sarkar R (2016) Development Core Team nlme: Linear and Nonlinear Mixed Effects Models. R package version 3.1-128

Price JD, Wright BR, Gross CL, Whalley WRDB (2010) Comparison of seedling emergence and seed extraction techniques for estimating the composition of soil seed banks. Methods Ecol Evol 1:151-157. doi:10.1111/j.2041-210X.2010.00011.x

Reid MA, Reid MC, Thoms MC (2016) Ecological significance of hydrological connectivity for wetland plant communities on a dryland floodplain river, MacIntyre River, Australia. Aquat Sci 78:139-158. doi:10.1007/s00027-015-0414-7

Riis T (2008) Dispersal and colonisation of plants in lowland streams: success rates and bottlenecks. Hydrobiologia 596:341-351. doi:10.1007/s10750-007-9107-0

Sainty GR, Jacobs SWL (2003) Waterplants in Australia. Sainty \& Associates, Sydney

Scown MW, Thoms MC, De Jager NR (2015) Floodplain complexity and surface metrics: influences of scale and geomorphology. Geomorphology 245:102-116. doi:10.1016/j.geomorph.2015.05. 024
Shiel RJ (1995) A guide to identification of rotifers, cladocerans and copepods from Australian inland waters. Co-operative Research Center for Freshwater Ecology, Canberra

Shiel RJ, Green JD, Nielsen DL (1998) Floodplain biodiversity: why are there so many species? Hydrobiologia 387(388):39-46. doi:10.1023/A:1017056802001

Ślusarczyk M, Grabowski T, Pietrzak B (2015) Quantification of floating ephippia in lakes: a step to a better understanding of high dispersal propensity of freshwater plankters. Hydrobiologia. doi:10.1007/s10750-015-2437-4

Smith LM, Haukos DA (2002) Floral diversity in relation to playa wetland area and watershed disturbance. Conserv Biol 16:964-974. doi:10.1046/j.1523-1739.2002.00561.x

Thomaz SM, Bini LM, Bozelli RL (2007) floods increase similarity among aquatic habitats in river-floodplain systems. Hydrobiologia 579:1-13. doi:10.1007/s10750-006-0285-y

Tockner KA, Lorang MS, Stanford JA (2010) River flood plains are model ecosystems to test general hydrogeomorphic and ecological concepts. River Res App 26:76-86. doi:10.1002/rra.1328

Tronstad LM, Tronstad BP, Benke AC (2005) Invertebrates seedbanks: rehydration of soil from an unregulated river floodplain in the south-eastern U.S. Freshw Biol 50:646-655. doi:10.1111/j. 1365-2427.2005.01351.x

Van Den Broek T, Van Diggelen R, Bobbink R (2005) Variation in seed buoyancy of species in wetland ecosystems with different flooding dynamics. J Veg Sci 16:579-586. doi:10.1111/j.16541103.2005.tb02399.x

Vandekerkhove J, Declerck S, Brendonck LUC, Conde-Porcuna JM, Jeppesen E, Meester LD (2005) Hatching of cladoceran resting eggs: temperature and photoperiod. Freshw Biol 50:96-104. doi:10.1111/j.1365-2427.2004.01312.x

Warr SJ, Thompson K, Kent M (1993) Seed banks as a neglected area of biogeographic research: a review of literature and sampling techniques. Prog Phys Geogr 17:329-347. doi:10.1177/ 030913339301700303

Water_Technology (2011) Hydrodynamic modelling of BarmahMillewa Forest. Murray-Darling Basin Authority, Canberra

Watkins SC, Nielsen D, Quinn GP, Gawne B (2011) The influence of leaf litter on zooplankton in floodplain wetlands: changes resulting from river regulation. Freshw Biol 56:2432-2447. doi:10.1111/j.1365-2427.2011.02665.x

Webb M, Reid M, Capon S, Thoms M, Rayburg S, James C (2006) Are flood plain-wetland plant communities determined by seed bank composition or inundation periods? Sediment Dynamics and the Hydromorphology of Fluvial Systems (Proceedings of a symposium held in Dundee, UK, July 2006). IAHS Publ. 306

Whitworth K, Baldwin DS, Kerr JL (2012) Drought, floods and water quality: drivers of a severe hypoxic blackwater event in a major river system (the southern Murray-Darling Basin, Australia). J Hydrol 450-451:190-198. doi:10.1016/j.jhydrol.2012.04.057 